\title{
Pyruvic acid egg medium for tubercle bacilli
}

\author{
M. H. HUGHES \\ From the Public Health Laboratory, Winchester
}

SYNOPSIS Sputum culture for tubercle bacilli on a solid egg medium containing glycerol was compared with culture on a similar medium containing pyruvic acid and no glycerol. Tubercle bacilli from the sputum of five out of 99 patients grew on pyruvic acid medium but not on glycerol medium. The addition of pyruvic acid is therefore essential when an egg medium is used for the cultural diagnosis of tuberculosis. There was no clear relation between catalase activity or isoniazid resistance and preferential growth of tubercle bacilli on pyruvic acid medium.

Marks (1963) has redirected attention to the use of pyruvic acid in solid egg media for the routine primary isolation of tubercle bacilli. This procedure had previously been advocated by Stonebrink (1958) as a result of earlier work by several authors quoted in his paper.

Marks compared a pyruvic acid medium with a similar medium containing glycerol and reported that nearly twice as many cultures grew on pyruvic acid alone as on glycerol alone. This finding showed that pyruvic acid was a good medium, but if the only advantage of its use were to detect the lingering remnants of scanty bacilli in treated patients, small laboratories might be excused the feeling that the addition of yet another medium to their normal routine was not justified by the marginal advantage secured. Cruickshank (1965) recommended the use of pyruvic acid medium 'for the isolation of human strains that are drug-resistant and difficult to grow'. The work reported here was undertaken in order to discover whether the use of a pyruvic acid egg medium ought to be considered mandatory in a laboratory undertaking routine sputum cultures for tubercle bacilli on solid egg media.

\section{METHODS}

Sputum specimens were received in $1 \mathrm{oz}$. Universal screw-capped glass containers. To each specimen was added an equal volume of $4 \%$ sodium hydroxide and the Universal containers were then shaken mechanically for 10 minutes and allowed to stand in an incubator at $37^{\circ} \mathrm{C}$. for a further $\mathbf{3 0}$ minutes. Each alkaline homogenate thus produced was decanted into a fresh Universal container containing $15 \mathrm{ml}$. of distilled water which was then centrifuged. Most of the supernatant fluid was discarded and the deposit, well mixed with the remaining fluid, was divided between a pyruvic acid and a glycerol slope by means of a disposable drinking-straw pipette. In alternate weeks either the pyruvic acid or the glycerol slopes were inoculated first. The cultures were inspected after a fortnight and thereafter weekly; negative cultures were discarded after six to seven weeks, save that cultures from microscopically positive specimens were not discarded before 10 weeks.

The medium resembled that of Marks (1963) and is made up as follows:

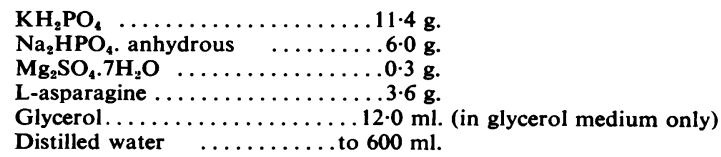

Boil to dissolve solids, cool to $60^{\circ} \mathrm{C}$., and add $30 \mathrm{~g}$. potato starch.

Heat to suspend starch, cool, and add to the wellmixed contents of 20 aseptically broken large fresh eggs. Mix and add $10 \mathrm{ml}$. of $2 \%$ solution of malachite green in distilled water.

Pyruvic acid (technical grade, British Drug Houses) is neutralized with $2 \mathrm{~N} \mathrm{NaOH}$ and $25 \mathrm{ml}$. of this mixture is added in the case of pyruvic acid medium from which the glycerol has been omitted.

After filtration through sterile gauze add 100,000 units of benzyl penicillin dissolved in $10 \mathrm{ml}$. of sterile distilled water. Dispense in $10 \mathrm{ml}$. amounts in Universal containers, slope, and sterilize in an autoclave at $75^{\circ} \mathrm{C}$. for 20 minutes on two successive days.

\section{RESULTS}

All sputa received during a period of 14 months were cultured on one slope of pyruvic acid and one slope of glycerol medium.

Excluding cultures in which one or both slopes were contaminated, 14 months' work yielded 365 
cultures positive for Mycobacterium tuberculosis derived from the sputa of 99 patients.

Two hundred and seventy-four cultures grew on both pyruvic acid and glycerol slopes. Growth was detected on one slope at least two weeks before the other on 14 occasions, on 11 of which the glycerol slope, and on three the pyruvic acid slope, yielded the faster growth.

Sixty-eight cultures grew only on pyruvic acid and 23 grew only on glycerol. When these were more closely analysed it was seen that 33 of the cultures growing only on pyruvic acid were derived from the sputa of five patients. Bacilli from patient A seemed to have become pyruvic-dependent half-way through the study period; patient $D$ yielded a few colonies on pyruvic acid alone on four occasions, whilst on a fifth both slopes were positive but the pyruvic acid grew a fortnight before the glycerol. Tubercle bacilli from the other three patients never grew on glycerol medium.

Apart from these five patients there were 35 positive cultures on pyruvic acid alone and 23 on glycerol alone. Many of these were cultures yielding from one to five colonies only and growth on one medium or the other may often have been due to the chance distribution of the few viable bacilli in the inoculum between one tube and the other, although the balance was still slightly in favour of the pyruvic acid medium. There was no patient whose tubercle bacilli consistently grew on glycerol only.

Preferential growth on pyruvic acid medium was not clearly related to the drug sensitivity of the bacilli. Sensitivities for the five pyruvic-dependent strains are shown in the Table.

\section{TABLE}

\begin{tabular}{|c|c|c|c|}
\hline DRUG & SENSITIVITY OF & $\begin{array}{l}\text { PYRUVIC-DE } \\
\text { BACILLI }\end{array}$ & TUBERCLE \\
\hline Patient & Streptomycin & Isoniazid & P.A.S. \\
\hline $\mathbf{A}$ & Resistant & Resistant & Resistant \\
\hline B & $\begin{array}{l}\text { Moderately } \\
\text { resistant }\end{array}$ & $\begin{array}{l}\text { Moderately } \\
\text { resistant }\end{array}$ & $\begin{array}{l}\text { Moderately } \\
\text { resistant }\end{array}$ \\
\hline D & Sensitive & Sensitive & Sensitive \\
\hline $\mathbf{N}$ & Sensitive & Resistant & Sensitive \\
\hline W & Sensitive & Sensitive & Sensitive \\
\hline
\end{tabular}

Sixteen other patients yielded among them 49 cultures of isoniazid-resistant tubercle bacilli, of which four were positive on pyruvic acid, one was positive on glycerol only, and 44 were positive on both. In seven of these patients glycerol gave slightly quicker (one week) or more luxuriant growth of tubercle bacilli, whereas in three patients there was better or quicker growth on pyruvic acid. Isoniazid-resistant bacilli from the remaining six patients grew equally well on both media.

\section{DISCUSSION}

In 94 out of 99 patients the use of a pyruvic acid e $\vec{g}$ medium was not clearly advantageous in compariso with a glycerol medium, and indeed in some cases glycerol yielded quicker and slightly more luxuriant growth. The significant observation was that tuberce bacilli from five out of 99 patients did not grow at aी on glycerol medium in repeated tests spread over considerable periods of time. If only the standa glycerol egg medium had been used these patients would have been diagnosed as arrested, nogg infectious, or non-tuberculous as far as bacterislogical criteria went. Five per cent of patients is too high a proportion to miss and the results reported here emphasize Marks' dictum (loc. cit.). 'If a choict had to be made, pyruvic medium would be recon mended in preference to glycerol medium'. A further point is that pyruvic acid medium, as Marks points out, will grow bovine tubercle bacilli more sat factorily than glycerol. No evidence on this point we s collected during the present work, however.

Marks stated that pyruvic acid discourages the growth of certain anonymous mycobacteria, and for this reason suggested that one slope of each medium should be used. Too few anonymous mycobacterya were isolated during this work to test Marks, statement, but three out of the five strains encountere्gd grew on both media and two on pyruvic acid alorf. M. kansasii, said to dislike pyruvic acid, did ngt occur. Some strains of $M$. tuberculosis grew mose quickly and slightly better on glycerol medium and this in itself may be an argument for retaining one glycerol slope in laboratories where the preparati每 of two different media is practicable.

Stonebrink (1961) found that all the isoniazioresistant cultures he tested grew better on pyruve acid that on glycerol medium. This was not the casse in this investigation where some isoniazid-resistapht strains seemed to be slightly favoured by glycerब, some to be indifferent, and some to be favoured pyruvic acid. Isoniazid resistance is not, therefore, the factor responsible for growth enhancement pyruvic acid.

Three out of five pyruvic-dependent strains and 12 out of 16 pyruvic-indifferent but isoniazif resistant strains of tubercle bacilli were available for testing for catalase production, for Stonebris (1958) suggested that neutralization of hydrogen peroxide might be the means by which pyruvic acid enhanced growth. Such neutralization would of course be more beneficial to catalase-negative than to catalase-positive bacteria.

All three pyruvic-dependent strains tested wese catalase-negative. Of 12 pyruvic-indifferent, is $\overrightarrow{8}-$ niazid-resistant strains, five were catalase-negative, 
three weak positive, and four positive. It appears therefore that although pyruvic-dependent strains lack catalase, catalase-negative strains are not necessarily pyruvic-dependent, and thus that catalase deficiency is not the whole explanation of the dependence of some strains of tubercle bacilli on pyruvic acid for growth on solid egg medium.
REFERENCES

Cruickshank, R. (1965). Medical Microbiology, 11th ed., p. 754. Livingstone, Edinburgh and London.

Marks, J. (1963). Mth. Bull. Minist. Hlth Lab. Serv., 22, 150.

Stonebrink, B. (1958). Acta tuberc. pneumol. scand., 35, 67.

(1961). Royal Netherlands Tuberculosis Association Selected Papers, 2, 1.

\section{Broadsheets prepared by the Association of Clinical Pathologists}

The following broadsheets (new series) are published by the Association of Clinical Pathologists. They may be obtained from Dr. R. B. H. Tierney, Pathological Laboratory, Boutport Street, Barnstaple, N. Devon. The prices include postage, but airmail will be charged extra.

13 The Identification of Serotypes of Escherichia coli Associated with Infantile Gastro-enteritis. 1956. JOAN TAYLOR. $1 \mathrm{~s}$.

16 Preservation of Pathological Museum Specimens. 1957. L. W. PROGER. 1s.

17 Cultural Diagnosis of Whooping-cough. 1957. B. W. LACEY. $1 \mathrm{~s}$.

20 Investigation of Porphyrin/Porphyria. 1958 (reprinted 1962). C. RIMINGTON. 2s.

23 The Dried Disc Technique for Bacterial Sensitivity Tests. 1959. R. W. FAIRBROTHER and J. C. SHERRIS. $1 \mathrm{~s}$.

24 Safe Handling of Radioactive Tissues in the Laboratory and Post-mortem Room. 1959. R. C. CURRAN. $1 \mathrm{~s}$.

26 The Periodic Acid-Schiff Reaction. 1959. A. G. E. PEARSE. 1s.

28 Daily Fatty Acid Excretion. 1960. A. C. FRAZER. 2s.

29 The Preparation of Bone for Diagnostic Histology. 1960. D. H. Collins. 2s.

30 Control of Accuracy in Chemical Pathology. 1961. G. H. GRANT. $4 \mathrm{~s}$.

31 Investigation of Haemorrhagic States with Special Reference to Defects of Coagulation of the Blood. 1961. E. K. BLACKBURN. 4s.

32 Detection of Resistance to Streptomycin, P.A.S., and Isoniazid in Tubercle Bacilli. 1961. R. CRUICKSHANK and S. M. STEWART. $2 \mathrm{~s}$.

33 The Laboratory Detection of Abnormal Haemoglobins. 1961 (reprinted 1965). H. LEHMANN and J. A. M. AGER. $4 \mathrm{~s}$.

34 Titration of Antistreptolysin O. 1961. H. GOODER and R. E. O. Williams. $2 s$.

35 The Estimation of Faecal 'Urobilinogen'. 1961. C. H. GRAY. $2 s$.
36 Quantitative Determination of Porphobilinogen and Porphyrins in Urine and Faeces. 1961. C. RIMINGTON. 3s. $6 \mathrm{~d}$.

37 The Paper Electrophoresis of Serum and Urinary Proteins. 1961. G. FRANGlen and N. H. MARTIN. 4s.

38 The Augmented Histamine Gastric Function Test. 1961. M. LUBRAN. 2 s.

39 Investigation of Haemolytic Anaemia. 1961. J. G. SELWYN. 2s.

40 Short-term Preservation of Bacterial Cultures. 1962. E. JOAN STOKES. 2s.

41 Serological Tests for Syphilis. 1962. A. E. WILKINson. 6s.

42 The Determination of Glucose 6-Phosphate Dehydrogenase in Red Cells. 1962. T. A. J. PRANKERD. 2s.

43 Mycological Techniques. 1962. R. W. RIDDELL. 3s. $6 \mathrm{~d}$.

44 The Laboratory Investigation of Catecholamine Secreting Tumours. 1963. M. SANDLER and C. R. J. RUTHVEN. 2s.

45 Diagnostic Test for Hereditary Galactosaemia. 1963. v. SCHWARTZ. $2 \mathrm{~s}$.

46 The Determination of Serum Iron and Total Iron Binding Capacity. 1963. A. JORDAN and D. A. PODMORE. 2s.

47 Nuclear Sexing. 1964. B. LENNOX and w. M. DAVIDSON. 2s.

48 The Laboratory Investigation and Control of the Defibrination Syndrome. 1964. R. M. HARDISTY, G. I. C. INGRAM, and A. A. SHARP. 3s. 6d.

49 Rapid Diagnostic Section Technique. 1965. N. J. BROWN and A. T. SANDISON. $2 \mathrm{~s}$.

50 The Collection, Preservation and Staining of Specimens for Gynæcological Cytology. 1965. ERICA WACHTEL. $4 s$. 